\title{
Uma análise sobre a política industrial durante o governo Lula (2003-2010)
}

\author{
Guilherme Jorge Silva* \\ Victor José Rocha de Lima** \\ Adriano José Pereira***
}

\begin{abstract}
Resumo
O Governo Lula (2002-2010) teve o grande mérito de recolocar as políticas industriais na pauta do dia, em um cenário de ausência de mais de vinte anos que privilegiava a estabilização econômica. As duas políticas - Política Industrial, Tecnológica e de Comércio Exterior (PITCE) e Política de Desenvolvimento Produtivo (PDP) -, não apenas introduziram novos recursos regulatórios e legislativos, como também mapearam a indústria brasileira na luz do século XXI em um nítido esforço amplo e conjunto dos agentes econômicos. A pretensão deste estudo é discutir os principais pontos propostos por essas duas políticas, dentro do arcabouço teórico do chamado estado desenvolvimentista e das linhas teóricas da economia industrial.
\end{abstract}

Palavras-chave: política industrial, PITCE, PDP.

\section{An analysis of industrial policy during government Lula (2003-2010)}

\begin{abstract}
The Lula's government (2002-2010) got the big merit to put back the industrial politicians on the agenda, after twenty years focusing on economic stability and leaving behind the industrial sector. The two politics - Política Industrial, Tecnológica e de Comércio Exterior (PITCE) and Política de Desenvolvimento Produtivo (PDP) -, not only put new regulatory resources and legislative, but also mapped the brasilian industry in a strong and aggregate perceptive effort from economics agents. The focus on this article is discuss about the main points proposed by this two politics, following the theoretical line of developmental state and theoricals lines of industrial economics.
\end{abstract}

Key Words: industrial politic, PITCE, PDP.

JEL: O02, O25

\footnotetext{
* Mestrando em Economia e Desenvolvimento na Universidade Federal de Santa Maria (UFSM). E-mail: guijorge2004@hotmail.com.

** Mestrando em Economia e Desenvolvimento na Universidade Federal de Santa Maria (UFSM). E-mail: victorj1@live.com.

*** Professor do Programa de Pós-Graduação em Economia e Desenvolvimento (PPGED) da Universidade Federal de Santa Maria (UFSM). E-mail: adrianoeconomia@ufsm.br
} 


\section{Introdução}

A industrialização é um dos tripés do núcleo duro do "estado desenvolvimentista", apontada como caminho ao progresso técnico e não há como falar, portanto, de desenvolvimento sem discutir industrialização (FONSECA, 2015, p.20-21). Os anos 1970 são de importância fundamental para entender o comportamento da economia brasileira e da sua indústria nos últimos 30 anos $(1980$ - 2010). Ao verificar-se que o chamado "Milagre Econômico" havia se mostrado equivocado, o país tinha as seguintes opções: seguir uma linha de ajustamento rígido que trazia benefícios para a concorrência e austeridade, contra um caminho que optava por mais um ciclo de crescimento econômico numa sustentação elevada de investimentos. O II PND encaixa-se na visão econômica desenvolvimentista de ação clara e consciente do Estado e responde, via investimento industrial, às limitações brasileiras verificadas na primeira Crise do Petróleo, promovendo no período entre 1983 e 1984, a contenção da dívida crescente e a reconstituição parcial das reservas monetárias (CASTRO \& SOUZA, 1985, p. 13-20).

Durante os anos 80, a crise altera a rota de crescimento do país para uma economia de estabilização, fazendo com que a política industrial perdesse totalmente o espaço nos planos macroeconômicos. Entre 1985 e 1987, tentativas de orientar o desenvolvimento industrial, com o objetivo de aumentar a eficiência e produtividade da indústria não foram postas em prática (CARNEIRO, 2002, p. 40-60; SUZIGAN, 1988, p.12-14). A situação brasileira era bastante delicada, fazendo com que alguns tímidos movimentos da iniciativa privada do país, no que se refere a diversificação no complexo eletrônico, fossem pífios (CANO \& SILVA, 2010, p. 2).

Já em 1990, tem-se o foco na abertura comercial e competitividade, durante o governo de Fernando Collor de Mello (1990-1992) que criou a chamada "Política Comercial e de Comércio Exterior" (PICE). Removeu-se a estrutura de barreiras não tarifárias para a exposição das empresas nacionais, fazendo com que a competitividade e concorrência passassem a ser parte da realidade das firmas brasileiras. Este cenário promoveu um ajustamento severo das empresas nacionais que acarretou em queda da produtividade, emprego e renda, além de falências das empresas (GUIMARÃES, 1996, P.6-13). 
Itamar Franco (1992-1994), logo em seguida, coloca em pauta a inflação como centro das discussões econômicas, via implementação do Plano Real (1994). O governo FHC (19942002), no primeiro momento, foi norteado pela manutenção da nova moeda, por planos de estabilização monetária e reformas constitucionais; e, no segundo momento, por uma crise expressa na incapacidade do Estado em estabilizar o emprego e promover renda e crescimento. Durante o período não houve promoção da indústria, do desenvolvimento ou mudança na trajetória política (GIAMBIAGI, 2011, P.190)

E é só a partir do governo Lula, que manteve o tripé macroeconômico do governo FHC, que a indústria volta para a pauta nacional. Primeiro, com a Política Industrial, Tecnológica e de Comércio Exterior (PITCE), que foi concebida com uma visão estratégica de longo prazo, e tinha em escopo a expansão da base industrial nacional a partir de sua capacidade inovativa. Esta política atuou em três principais pilares: Políticas horizontais (voltadas para inovação e desenvolvimento tecnológico, inserção externa/exportações, modernização industrial, ambiente institucional), ações verticais em setores estratégicos (software, semicondutores, bens de capital, fármacos e medicamentos) e em atividades portadoras de futuro (biotecnologia, nanotecnologia e energias renováveis). Além disso, instituiu-se em 2008 a Política de Desenvolvimento Produtivo (PDP), que tinha como pretensão fortalecer a economia via diálogos com o setor privado e estabelecimento de metas. Tanto a PITCE quanto a PDP introduziram novos recursos regulatórios e legislativos e possibilitaram o mapeamento da indústria brasileira na luz do século XXI.

Diante do exposto, o objetivo desse trabalho é analisar as metas e resultados propostos por essas duas políticas dentro do arcabouço teórico do chamado estado desenvolvimentista e da linha teórica da economia industrial evolucionária. Para isso na primeira parte teremos uma revisão sobre a economia industrial e um panorama histórico brasileiro das medidas econômicas de 1970 até 2002. A terceira etapa a metodologia empregada, a quarta apresenta os dois períodos do Governo Lula (2003-2006/2007-2010) e suas respectivas políticas industriais: PITCE e PDP. Ao final é apresentada uma conclusão sobre as políticas postas em prática naquele cenário.

\section{Arcabouço teórico e contexto histórico}


Temos, ao menos, dois caminhos para a política industrial: o de regulação - que envolve processos de arbitragem concorrencial como: política antitruste, propriedade intelectual, política comercial, controle e administração de preços, dentre outros - e o regime de incentivos - estímulos financeiros e físcais como juros subsídiados, modificação na estrutura tarifária, deduções físcais, crédito e financiamento de longo prazo, incentivos aos gastos de pesquisa e desenvolvimento (P\&D), etc. (FERRAZ, 2009, p.230-231).

A teoria industrial, ainda, distingue as ações da política entre verticais e horizontais. As ações verticais são aquelas que privilegiam determinados setores em detrimento de outros, onde temos medidas discricionárias que se justificam pelas características do setor delimitado. Nesse caso, observamos elevado poder de encadeamento na cadeia produtiva, grande dinamismo potencial, retornos crescentes de escala e geração de um maior valor agregado. Em termos gerais, temos uma política mais incisiva sobre o tecido econômico. Já as chamadas políticas horizontais procuram melhorar o desempenho da economia em sua totalidade, sem a especificação de um setor e enfatizando as ações governamentais para as condições gerais da economia. Medidas consideradas horizontais são, por exemplo, melhorias da infraestrutura (portos, aeroportos, etc.) e melhorias educacionais e de ciência e tecnologia (FERRAZ; PAULA; KUPFER, 2002, p.558-560).

Existe, como esperado pelas características acima, uma polarização sobre as ações do Estado na política industrial. O contraste quanto ao escopo da política industrial utilizada pelo governo se deve, conforme Suzigan e Furtado (2006, p. 164-165) às linhas teóricas acerca da industrialização e função do Estado. Temos, resumidamente, 3 grandes linhas de visões teóricas sobre a temática: A ortodoxa, a desenvolvimentista e a evolucionária.

A visão Ortodoxa defende que a ação por meio das políticas industriais deve ser executada apenas quando verificadas falhas de mercado, como em caso de estruturas e condutas competitivas. A ação, portanto, é meramente corretiva e horizontal, cabendo aos agentes privados o curso industrial. Essa linha teórica, portanto, evita as chamadas "falhas de governo". A liberalização comercial daria maior integração internacional, dando oportunidade de desenvolvimento de processos industriais mais robustos. Não podemos deixar de lado, que a consideração de simetria de informações e de racionalidade ilimitada não deixa espaço para 
Revista Catarinense de Economia -RCE

APEC - Associação dos Pesquisadores em Economia Catarinense

10 Semestre de 2018 - www.apec.pro.br/rce

incertezas no campo econômico, dando margem para uma série de deficiências empíricas (FERRAZ, 2009, p.232-235).

Já a visão desenvolvimentista atribui em grande parte a participação do Estado nos fenômenos econômicos. É nessa linha que se encaixam os pensamentos de Celso Furtado e Raúl Presbisch, pensamentos que deram a tônica do crescimento econômico por mais de 40 anos no Brasil. Nessa visão, a história e a trajetória de longo prazo são importantes, tendo o Estado como agente decisório. Todos os instrumentos de política econômica disponíveis são destinados para a industrialização, com a clara noção da importância de acumulação de capital físico e intelectual (FERRAZ, 2009, p.232-235).

Vale a nota de que essa vertente de pensamento tem como pensadores homens que, em sua maioria, ocuparam cargos nos Governos de seus países - como é o caso, por exemplo, tanto de Prebisch quanto de Furtado. É destacável que a consciência da importância do Estado na industrialização ganhou contornos próprios na América Latina através da CEPAL e suas linhas teóricas de desenvolvimento dentro do pensamento Centro-Periferia. Ou seja, no Brasil é adotado um modelo de desenvolvimento dentro de uma lógica macroeconômica mundial. A adoção desse modelo não define, de forma alguma, a instrumentalização e conceitualização do que é desenvolvimento ou do modo operacional do Estado. Como podemos ver nos trabalhos de Fonseca (2015, p. 20-21) as linhas teóricas acerca do chamado "Estado desenvolvimentista" são diversas (apesar de compartilharem um núcleo duro em comum) e que, muitas vezes, a ação prática e a teoria do que se concebe como desenvolvimento e "estado desenvolvimentista" são descoladas.

A terceira interpretação é a corrente evolucionária neoschumpeteriana. Aqui temos a combinação do marco teórico desenvolvido, com maior destaque, por Nelson e Winter (1982, cap. 12) no papel estratégico da inovação. A inovação encontra-se no centro das atenções e do processo de desenvolvimento, sendo o principal motor do capitalismo. Nos escritos de Joseph Schumpeter se enfatiza a importância do estudo fundamental não do ponto de equilíbrio outrora defendido pela linha econômica ortodoxa, e sim o processo que se dá, nos mais diversos planos, na análise da firma e da indústria. A destruição criativa, no processo de acumulação no sistema capitalista, faz com que esse mesmo sistema esteja em constante mudança e transformação, como um organismo vivo, onde as velhas estruturas dão espaço para novas. A observação dessa economia está no meio de regularidades, processos, rotinas, metarotinas e regras. Além dessas características, faz-se um entendimento mais factual do 
comportamento do indivíduo como agente criativo, com capacidade inventiva e limitação empírica.

A contribuição evolucionária, segundo Cassiolato e Erber (1997) permite uma atualização não apenas da agenda econômica nacional da industrialização como também propõe instrumentos para a melhora e atualização tecnológica do tecido econômico nacional, uma vez que coloca ao centro do debate as questões voltadas para a inovação, tecnologia e conhecimento.

\subsection{Contexto histórico}

Especificamente no caso brasileiro, os anos 1970 são fundamentais para se entender os rumos da economia brasileira nos últimos 30 anos (1980-2010). A escolha entre crescimento baseado em industrialização pesada que terminaria o ciclo do PSI norteado pelo chamado II Plano Nacional de Desenvolvimento (II PND), era uma ação um tanto quanto arriscada, uma vez que o "Milagre Econômico" deixou o país em uma situação delicada do ponto de vista da dívida externa, principalmente com o primeiro choque do petróleo em 1973. Portanto, o país tinha duas opções - ajustamento rígido que beneficiava a concorrência e a austeridade ou um caminho por mais um ciclo de crescimento econômico numa sustentação elevada de investimentos. Em outras palavras, entrávamos em uma marcha forçada em nome do progresso industrial brasileiro. O II PDN se encaixa na visão econômica desenvolvimentista de ação clara e consciente do estado e responde, via investimento industrial, as limitações brasileiras verificadas na primeira Crise do Petróleo. Os resultados do II PND podem ser verificados já no início da década de 1980, mais especificamente entre 1983 e 1984, uma vez que os investimentos realizados no penúltimo governo militar garantiram a contenção da dívida crescente e a reconstituição parcial das reservas monetárias (CASTRO \& SOUZA, 1985, p.13-20).

Apesar dos resultados verificados entre 1983 e 1984, o Brasil seguiria por duas décadas em um cenário desanimador. A crise dos anos 1980 alterou a rota de crescimento do país para uma economia de estabilização, fazendo com que a política industrial perdesse totalmente o espaço nos planos macroeconômicos. A preocupação, naquele momento, era deter a inflação e voltar para uma trajetória de crescimento dentro dos moldes neoliberais que 
Revista Catarinense de Economia -RCE

APEC - Associação dos Pesquisadores em Economia Catarinense

10 Semestre de 2018 - www.apec.pro.br/rce

focalizavam o pagamento da dívida, em um cenário de ruptura de financiamento internacional. No intervalo de 1985-1987 é vista uma tentativa de orientar o desenvolvimento industrial, com o objetivo de aumentar a eficiência e produtividade. Essas estratégias, contudo, não foram colocadas em práticas, o que demonstra uma falta de consenso em relação as metas estabelecidas e a falta de articulação entre o Estado e o setor privado. Em suma, o desenvolvimentismo observado pelo PSI até o final dos anos 1970 tinha ficado para trás e ficaria evidente o cenário de desordem que a economia brasileira entrava na década de 1990 (CARNEIRO, 2002, p.40-60; SUZIGAN, 1988, p.12-14).

Não podemos desconsiderar alguns esforços do setor público e até mesmo do empresariado nacional ainda nos anos 1980, como bem observou Wilson Cano e Ana Lúcia Gonçalves da Silva (2010, p.3). Houve um esforço, na segunda metade da década de 1980, em capturar oportunidades nas fronteiras de informação - como informática, biotecnologia, etc. tendo, portanto, reconhecimento claro que no âmbito internacional mudanças profundas estavam sendo efetuadas com o advento de novas tecnologias. A situação brasileira, contudo, era extremamente delicada, o que fez com que os tímidos movimentos da iniciativa privada para a diversificação no complexo eletrônico fossem pífios. Era impossível um efeito desses movimentos sem uma articulação clara, consciente e efetiva de políticas industriais.

Os anos 1990 deixariam claros os novos rumos da economia brasileira. Baseada no chamado "Consenso de Washington" 1 ", as ideias aplicadas para a política econômica brasileira eram baseadas por princípios relacionados com as "forças de mercado". Essas forças promoveriam a modernização produtiva e a melhoria da competitividade num aporte generoso de capital, tecnologia e conhecimento oriundos do exterior. O país, assim, se encaminharia para o mundo globalizado.

Com foco na abertura comercial e na competitividade, o Governo de Fernando Collor de Mello (1990-1992) criou a chamada "Política Industrial e de Comércio Exterior" (PICE). A Exposição de Motivos da Medida Provisória 158, divulgada no dia 15 de março de 1990, faz as primeiras indicações relativas aos objetivos e diretrizes da nova política. O documento liga os planos de elevação do salário real com a política industrial, objetivando-se a maior abertura e desregulamentação da economia. Caberia ao Estado criar regras estáveis e transparentes a

\footnotetext{
${ }^{1}$ Série de recomendações econômicas internacionais elaboradas pelo economista norte-americano John Williamson em 1989, com forte base liberal.
} 
Revista Catarinense de Economia -RCE

APEC - Associação dos Pesquisadores em Economia Catarinense

10 Semestre de 2018 - www.apec.pro.br/rce

fim de nortear a competitividade das empresas nacionais. Dentre os instrumentos utilizados previam-se os incentivos ao investimento, à produção e exportação, apoio à capacitação tecnológica das firmas nacionais, bem como a promoção de empresas nascentes em áreas de alta tecnologia. Removeu-se a estrutura de barreiras não tarifárias para a exposição das empresas nacionais, tornando a questão competitiva e concorrencial uma realidade para as firmas brasileiras (GUIMARÃES, 1996, p.6-8).

A opção de medidas horizontais ao invés de medidas verticais tinha uma lógica clara dentro do contexto de abertura e mudança de trajetória na política industrial: As firmas mais aptas sobreviveriam ao cenário competitivo, e seriam integradas ao mercado global. Contudo, o que se observou como resultado das novas diretrizes da política industrial foi um severo ajustamento das empresas nacionais que acarretou em redução de produtividade, emprego e renda, além, é claro, de diversas falências. Apesar do resultado perverso e do fracasso do Governo Collor, temos que considerar: a instalação de câmaras setoriais que permitiram a negociação entre empresários, funcionários e governos para a reativação de alguns setores; o MERCOSUL concedeu tratamento diferenciado à abertura comercial regional; alguns setores industriais, como por exemplo o automobilístico, tiveram regimes especiais de proteção para promover a produção local e o investimento (CANO E SILVA, 2010, p.4-5; SARTI E LAPLANE, 2006, p. 272).

O fim do governo Collor e início do governo Itamar Franco (1992-1994) coloca a questão inflacionária, mais uma vez, no centro das discussões econômicas com a implementação do bem-sucedido Plano Real (1994). O Governo FHC (1994-2002) seria norteado, em grande medida, na manutenção da nova moeda, em um primeiro momento com uma agenda marcada por estabilização monetária e reformas constitucionais. Uma das ações centrais verificadas nesse primeiro Governo é exatamente a privatização de diversas empresas estatais, criando-se pela primeira vez em mais de 50 anos uma nova relação entre estadomercado, sendo transferido boa parte do patrimônio estatal para empresas privadas. Mesmo com os recursos oriundos em parte dessa onda de privatizações, não foi possível conter a dívida pública, que acabou explodindo ainda no primeiro mandato (COUTO E ABRUCIO, 2003, p. 278-280).

Um fator importante, assinalado por Mattos (2006, p.151-152) é a criação do novo Estado regulador - que tem como símbolo a criação das Agências Nacionais Reguladoras - e representa uma clara descentralização do poder do Presidente da República e seus ministros, 
Revista Catarinense de Economia -RCE

APEC - Associação dos Pesquisadores em Economia Catarinense

10 Semestre de 2018 - www.apec.pro.br/rce

na tentativa de se criar novos mecanismos jurídicos e institucionais na participação social e na criação e formulação da regulamentação de diversos setores. A criação de uma burocracia estatal para a regulação das falhas de mercado marcou a redefinição do poder político para a formulação de políticas públicas para setores estratégicos da economia, como energia, telecomunicações, transporte, saúde, etc.

O segundo governo FHC (1998-2002) foi marcado pela crise cambial e pela evidente incapacidade do Estado em promover emprego, renda e crescimento. Apesar do controle inflacionário o Brasil estava, mais uma vez, em um cenário desanimador que é assinalado por diversos indicadores econômicos. Não houve promoção da indústria, do desenvolvimento ou mudança na trajetória das políticas econômicas. A economia, a partir de 1999, estava baseada no chamado "Tripé Macroeconômico" como resposta nacional aos desdobramentos da crise externa. O Tripé é, basicamente, composto por metas inflacionárias, câmbio flutuante e geração de superávit primário, onde o Banco Central (BC) fica livre em atuar com a taxa de juros caso a inflação preocupe. Se há um problema com o Balanço de Pagamentos (BP), o câmbio se ajusta e melhora a conta corrente, e se a dívida pública cresce é necessário calibrar o superávit primário. O conjunto desses três fatores capacitam o estado para atacar os principais desequilíbrios macroeconômicos de forma conjunta e integrada, o que até então era um problema para diversos governos (GIAMBIAGI, 2011, 190-193).

O período do fim do século XX e início do século XXI no Brasil é marcado por um impasse macroeconômico. A mudança da trajetória da política econômica no início dos anos 1980 em favor da estabilização fez com que as políticas industriais ficassem em segundo plano, mesmo com algumas tentativas isoladas que se mostraram infrutíferas. Apesar de resolvermos o problema da inflação com o Plano Real no governo Itamar Franco, questões acerca da capacidade tecnológica, difusão de conhecimento e produtividade industrial não foram solucionadas. Tal incapacidade refletiu não apenas no crescimento medíocre verificado nas duas décadas - que levam o epíteto de "décadas perdidas" -, como também na capacidade de articulação entre Estado e iniciativa privada para ações efetivas ao desenvolvimento nacional. Os desafios do governo Luís Inácio Lula da Silva (2003-2010), para além das expectativas de mercado e agentes internacionais, eram imensas no que concerne ao Estado, indústria e políticas efetivas para o desenvolvimento nacional, sem perder de vista questões já resolvidas e fundamentais, como a inflação. 


\section{Metodologia}

Apresenta-se, inicialmente, uma descrição das políticas industriais adotadas pelo governo Lula durante os seus dois períodos (2003-2006) e (2007-2010), entre elas a Política Industrial Tecnológica e de Comércio Exterior (PITCE) e a Política de Desenvolvimento Produtivo (PDP), segundo SALERNO; DAHER (2006). A partir da descrição dessas políticas serão observados seus impactos sobre alguns indicadores, capazes de revelar um grau de evolução da indústria e na produtividade do país.

Entre os indicadores serão expostos: a Formação Bruta do Capital Fixo (FBCF), obtida no IBGE, que é a operação do Sistema de Contas Nacionais (SCN) que registra a ampliação da capacidade produtiva futura de uma economia por meio de investimentos correntes em ativos fixos (bens produzidos factíveis de utilização repetida e contínua em outros processos produtivos por tempo superior a um ano sem, no entanto, serem efetivamente consumidos pelos mesmos). Dispêndio empresarial em Pesquisa e Desenvolvimento (P\&D), obtido na PINTEC, que normalmente se refere à atividades de longo prazo e/ou orientadas ao futuro, relacionadas à ciência ou tecnologia, usando técnicas similares ao método científico sem que haja resultados pré-determinados mas, com previsões gerais de algum benefício comercial; e exportações brasileiras gerais no cenário global e as exportações de micro e pequenas empresas, obtidos no Secex/MDIC, onde estes indicadores podem revelar o grau de internacionalização das empresas e tecnologias brasileiras, além de suas competitividades.

\section{Avaliação da política industrial no governo Lula (2003-2010)}

O primeiro Governo Lula mantém a política macroeconômica do Governo FHC baseada, principalmente, no Tripé metas inflacionárias, câmbio flutuante e superávit primário. Segundo relatório do BACEN (2015), em novembro de 2003, a taxa de juros SELIC fechou em 11,5\% a.a e com uma inflação em 9,3\% a.a. O crescimento do Produto Interno Bruto (PIB) daquele ano foi de $1,1 \%$ e a desvalorização no final do governo FHC estimulou as exportações nacionais, beneficiando a Balança Comercial (BC) e os produtos manufaturados (IBGE). 
Se, por um lado, as políticas macroeconômicas mantiveram o seu padrão, por outro a indústria volta para a pauta nacional com o lançamento, no dia 31 de março de 2004, da Política Industrial, Tecnológica e de Comércio Exterior (PITCE).

\subsection{O primeiro governo Lula: Política Industrial, Tecnológica e de Comércio Exterior (PITCE)}

Segundo a Agência Brasileira de Desenvolvimento Industrial (ABDI), a PITCE foi concebida com uma visão estratégica de longo prazo que tem em sua coluna vertebral a expansão da base industrial nacional, a partir da melhoria de sua capacidade inovativa, atuando em três principais pilares: políticas horizontais (voltadas para inovação e desenvolvimento tecnológico, inserção externa/exportações, modernização industrial, ambiente institucional); ações verticais em setores estratégicos (software, semicondutores, bens de capital, fármacos e medicamentos); e, em atividades portadoras de futuro (biotecnologia, nanotecnologia e energias renováveis).

Dado o caráter diversificado da indústria brasileira, a PITCE tem em seu escopo uma ampla proposta de políticas tanto horizontais quanto verticais. Reconhece-se que o mundo está marcado por uma forte dinâmica processual, onde a inovação é fundamental e o sucesso da política pública, portanto, é determinado pela orientação em alcançar-se os padrões internacionais e aumentar-se a capacidade inovativa das empresas nacionais.

Para que a proposta fosse realizada com êxito, foi necessário um árduo esforço político e econômico para que as diretrizes do programa tivessem evolução conjunta e sincronizada. Em outras palavras, o Governo utilizou um amplo arcabouço institucional e financeiro para concretizar a PITCE. Sabemos que duas décadas de ausência de políticas industriais fizeram com que o país, necessariamente, revesse os instrumentos legais e todo aparato econômico.

\subsubsection{Ações horizontais}

Um dos aspectos fundamentais da PITCE é, sem dúvida alguma, o marco regulatório. A Lei da Inovação foi sancionada pelo presidente em dezembro de 2004 e estabelece a interação entre universidades, Estado e setor privado permitindo, por exemplo, não apenas o 
Revista Catarinense de Economia -RCE

APEC - Associação dos Pesquisadores em Economia Catarinense

10 Semestre de 2018 - www.apec.pro.br/rce

investimento público no setor privado, como também a criação de empresas por parte de pesquisadores para trabalharem e desenvolverem suas atividades relacionadas com a inovação. Um dos destaques é a subvenção econômica para as empresas que envolveu R\$ 510 milhões, segundo dados da Finep em 2006, sendo 300 milhões para semicondutores, softwares, fármacos e medicamentos e bens de capital, com foco na cadeia produtiva de combustíveis e biocombustíveis (SALERNO; DAHER, 2006).

A chamada Lei do Bem foi regulamentada em junho de 2006 e prevê um conjunto de instrumentos para apoio à inovação com o objetivo de reduzir não apenas os riscos da empresa, como também os custos através de incentivos fiscais. A Lei é um usufruto automático, isto é, não precisa de submissão prévia de projeto e nem pedir aprovação, basta lançar os dispêndios em P\&D na instrução normativa da Receita Federal. As medidas de incentivo incluem redução do IPI para equipamentos de pesquisa, crédito do imposto de renda (IR) na fonte sobre royalties e assistência técnica contratada no exterior. As deduções relacionadas com P\&D são realizadas de forma automática. Além disso, a mesma lei permite a subvenção da remuneração de mestres e doutores nas empresas, com alocação de $\mathrm{R} \$ 60$ milhões para esse fim (SALERNO E DAHER, 2006, p.11-52).

As empresas de informática têm redução de IPI em contrapartida ao investimento feito em P\&D equivalente a 5\% do seu faturamento, previsto na Lei da Informática. Já a Lei de Biossegurança, de novembro de 2005 , versa sobre a pesquisa em organismos geneticamente modificados e com células-troncos, apesar de não modificar o acesso aos recursos genéticos com revisão apenas em 2015 (SALERNO; DAHER, 2006, p.11-52; PLANALTO, 2015).

Tão importante quanto a regulação são mecanismos de financiamento. O BNDES entra, novamente, nos financiamentos para inovação fazendo com que o sistema BNDESFinep alcançasse, em 2006, cerca de $\mathrm{R} \$ 3$ bilhões em recursos disponíveis para financiamento - com juros abaixo do mercado (ABDI).

A nova dinâmica mundial exige a formação de recursos humanos qualificados, o que chamamos em economia de capital humano. O Brasil sempre teve problema nessa área, o que incentivou a ampliação não apenas do número de instituições de ensino superior no país, como também na ampliação de formação de pós-graduandos e bolsistas. O crescimento pode ser visto na Tabela 1.

Tabela 1- Bolsistas por grandes áreas no Brasil, 1995 


\begin{tabular}{|l|c|c|c|}
\hline Grandes Áreas & Doutorado & Mestrado & Total \\
\hline CIÊNCIAS AGRÁRIAS & 818 & 1.417 & 2.235 \\
CIÊNCIAS BIOLÓGICAS & 889 & 963 & 1.852 \\
CIÊNCIAS DA SAÚDE & 1.037 & 1.932 & 2.969 \\
CIÊNCIAS EXATAS E DA TERRA & 1.035 & 1.154 & 2.189 \\
CIÊNCIAS HUMANAS & 1.347 & 2.189 & 3.536 \\
CIÊNCIAS SOCIAIS APLICADAS & 554 & 1.475 & 2.029 \\
ENGENHARIAS & 1.227 & 1.869 & 3.096 \\
GRANDE ÁREA NÃO INFORMADA & 5 & 4 & 9 \\
LINGÜÍSTICA, LETRAS E ARTES & 407 & 852 & 1.259 \\
MULTIDISCIPLINAR & 69 & 182 & 251 \\
\hline
\end{tabular}

Fonte: Elaboração própria, a partir de dados extraídos da CAPES.

Como podemos ver o número de bolsistas pós-graduandos no Brasil aumentou significativamente, confrontando os dados da Tabela 1 e da Tabela 2. Quando olhamos mais de perto para as grandes áreas, verifica-se que há um domínio das ciências da saúde, ciências agrárias e das ciências humanas, seguida em quarta posição pelo número de engenharias. Esse dado é importante, pois reflete o foco de formação do país, onde o número de mestrandos e doutores em engenharias mais que dobrou de 1995 até 2010. Não consideramos, ainda, o número de desistências e evasões que não são contabilizados pelos números aqui registrados.

Tabela 2- Bolsistas por grandes áreas do Brasil, 2010

\begin{tabular}{|l|c|c|c|}
\hline Grandes Áreas & Doutorado & Mestrado & Total \\
\hline CIÊNCIAS AGRÁRIAS & 3.093 & 4.492 & 8.059 \\
CIÊNCIAS BIOLÓGICAS & 2.569 & 3.187 & 6.352 \\
CIÊNCIAS DA SAÚDE & 3.563 & 4.393 & 8.356 \\
CIÊNCIAS EXATAS E DA TERRA & 2.667 & 3.768 & 6.843 \\
CIÊNCIAS HUMANAS & 3.138 & 4.962 & 8.253 \\
CIÊNCIAS SOCIAIS APLICADAS & 1.261 & 2.803 & 4.130 \\
ENGENHARIAS & 2.585 & 4.458 & 7.470 \\
GRANDE ÁREA NÃO INFORMADA & 497 & 1.025 & 1.606 \\
LINGÜÍSTICA, LETRAS E ARTES & 1.241 & 1.941 & 3.227 \\
MULTIDISCIPLINAR & 1.327 & 2.328 & 3.811 \\
\hline
\end{tabular}

Fonte: Elaboração própria, a partir de dados extraídos da CAPES. 
Até 2006, a inserção externa brasileira em termos de manufaturados com alta tecnologia teve um salto na participação da pauta exportadora: De 14,9\% de 1999 até 2003 para 28,1\% em 2005/2004, e uma notável queda na participação de commodities no intervalo de 2003 a 2005 de 40,3\% para 38,2\%. Em termos gerais, a participação do Brasil em exportações no mercado internacional aumentou de 0,96\% em 2002 para 1,17\% em 2005 $(\mathrm{ABDI})$.

Não podemos perder de vista que a inserção nacional não fica por conta apenas da pauta exportadora do país, leva-se em conta, também, a internacionalização das empresas e tecnologias brasileiras e a manutenção da competitividade de suas empresas.

\subsubsection{Ações verticais}

Quatro opções estratégicas foram definidas pela forte relação com a inovação e pela vulnerabilidade brasileira nesses setores: semicondutores, software, bens de capital e fármacos e medicamentos.

Dado que a fabricação de semicondutores é incipiente no Brasil, focou-se em dois pilares de ação: capacitação local e atração de investimentos, sendo um dos primeiros resultados dessa política, a inauguração em Atibaia (SP) da primeira fábrica em 25 anos de módulos de memórias para computadores, telefones celulares e aplicações diversas. Existe, também, a preocupação com a capacitação de pessoas, que pode ser observado na instalação do Centro de Excelência Tecnológica em Tecnologia Eletrônica (Ceitec), um projeto orçado em R\$ 155 milhões.

O Brasil é um dos maiores mercados de Software do mundo, com crescimento acima do PIB. A participação de softwares brasileiros, contudo, é bastante reduzida no mercado internacional. A linha de financiamento do BNDES - novo Prosoft - envolveu produtor e consumidor em um montante de R \$ 521 milhões de investimentos com apoio para fusões e consolidação de empresas com ganhos de escala (SALERNO; DAHER, 2006, p.11-52).

Os bens de capital são não apenas a parte fundamental da dinamização da economia como também a área de maior dificuldade de desenvolvimento no Brasil. Os recursos destinados para esse segmento são vultuosos (para mais de 1 bilhão), mas ao que tudo indica o principal problema está na capacidade absortiva de novas tecnologias, do que apenas na aquisição de novas máquinas e equipamentos. 
Por último, temos as ações de subvenção e incentivo de exploração dos fármacos e da biotecnologia com uma grande ação conjunta de longo prazo (10 anos), envolvendo recursos dos fundos de saúde e do Profarma.

\subsubsection{Atividades portadoras do futuro}

Aqui temos as áreas com potencial para transformar radicalmente produtos, processos e formas de uso no médio e longo prazo. São os programas para biomassa/energias renováveis, com a manutenção da liderança brasileira em tecnologia e negócios da cadeia do álcool; o aproveitamento de crédito de carbono, energia solar e eólica; e, os programas voltados para a Nanotecnologia que, apesar de recursos iniciais modestos, sugerem apontamentos e aproximações setoriais para gerar não apenas mudanças científicas como também oportunidades comerciais (ABDI).

\subsection{O segundo governo Lula e a continuidade da pauta industrial}

A reeleição de Lula nas eleições de 2006 permitiu a continuidade da PITCE com a Política de Desenvolvimento Produtivo (PDP). Instituída em 2008 com o objetivo de fortalecer a economia, foi norteada por diálogos com o setor privado e estabelecimento de metas. A agenda foi elaborada sob a coordenação do Ministério do Desenvolvimento, Indústria e Comércio Exterior (MDIC), em conjunto com o Ministério da Fazenda e o BNDES.

\subsubsection{A Política de Desenvolvimento Produtivo (PDP)}

A apresentação das macrometas e atividades da PDP deixa clara a importância da PITCE por construir um arcabouço legal-regulatório e fortalecer as instituições de apoio à política, como o Conselho Nacional de Desenvolvimento Industrial (CNDI) e a Agência Brasileira de Desenvolvimento Industrial (ABDI), dentre outras.

A PDP estabeleceu quatro macrometas no seu triênio: Ampliação da Formação Bruta do Capital Fixo (FBCF) de 17,4\% para 21\% em 2010; a elevação do dispêndio empresarial em P\&D de 0,51\% do PIB de 2005 para 0,65\% em 2010; a ampliação das exportações 
brasileiras no cenário global, de 1,18\% em 2007 para 1,25\% em 2010; e, aumentar em 10\% o número de micro e pequenas empresas (MPEs) exportadoras em relação ao valor registrado em 2006 (11.792) (ABDI).

A manutenção de um investimento em taxas superiores ao crescimento do PIB para a FBCF começou muito bem, mas teve um impacto negativo com a crise em 2008. O Governo reagiu disponibilizando recursos financeiros para o crescimento da economia brasileira, o que foi capaz de manter o crescimento, mas não com a força necessária para atingir a meta estabelecida.

Quadro 3 - Taxa de investimento do Brasil - 2006-2010 (\%)

\begin{tabular}{|l|l|}
\hline 2006 & 17,3 \\
\hline 2007 & 18,1 \\
\hline 2008 & 19,5 \\
\hline 2009 & 19,2 \\
\hline 2010 & 18,4 \\
\hline
\end{tabular}

Fonte: Elaboração própria, a partir de dados extraídos do IBGE.

\section{Investimento (\%)}

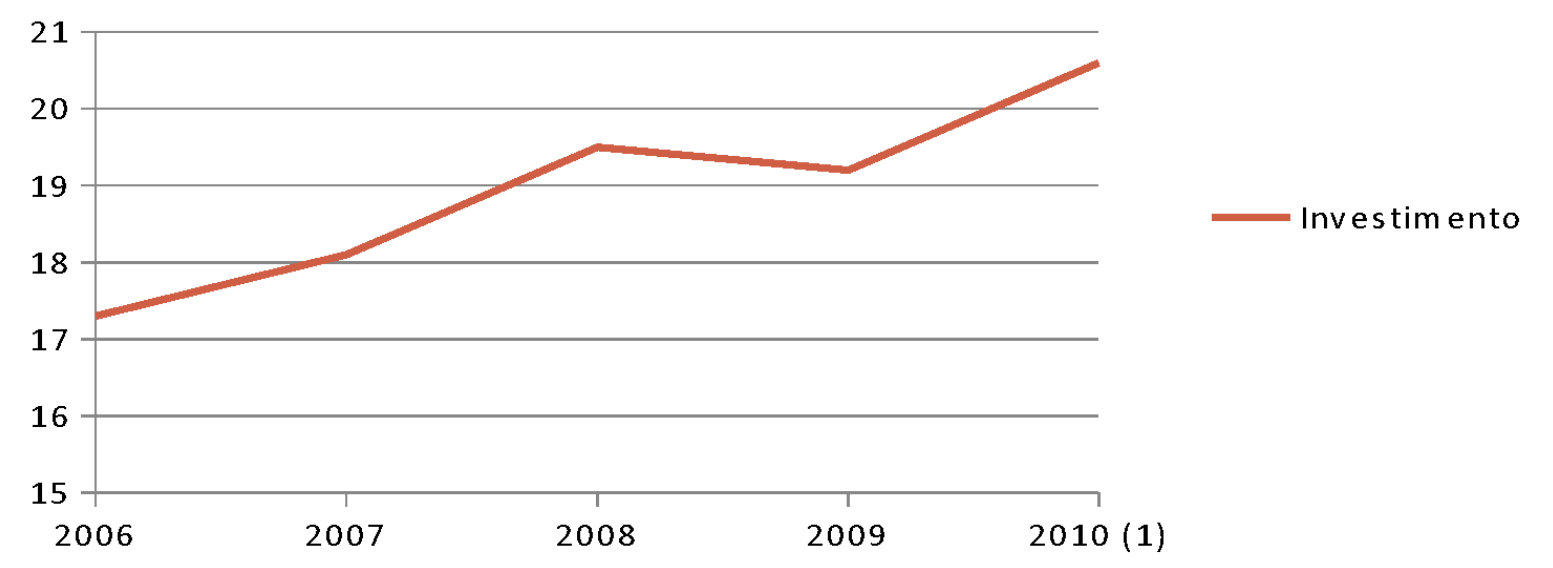

Gráfico 1 - Taxa de investimento do Brasil - 2006-2010 (\%)

Fonte: Elaboração própria, a partir de dados extraídos do IBGE.

Os gastos em P\&D ficaram bem longe de cumprir, dentro ou fora do prazo, a meta de 0,65\%, uma vez que em 2011 o dispêndio em P\&D foi de 0,59\%. Para alcançar a meta dentro 
do prazo era esperado uma taxa de crescimento anual de 11,5\% no intervalo de 2005-2010 considerando o crescimento anual do PIB de 5\% (PINTEC).

A participação brasileira nas exportações mundiais, mesmo em cenário de crise, aumentou de 1,18\% em 2007 para 1,26\% em 2009, o que já supera a meta proposta de 1,25\%. Em 2010 ultrapassou 1, 35\%.

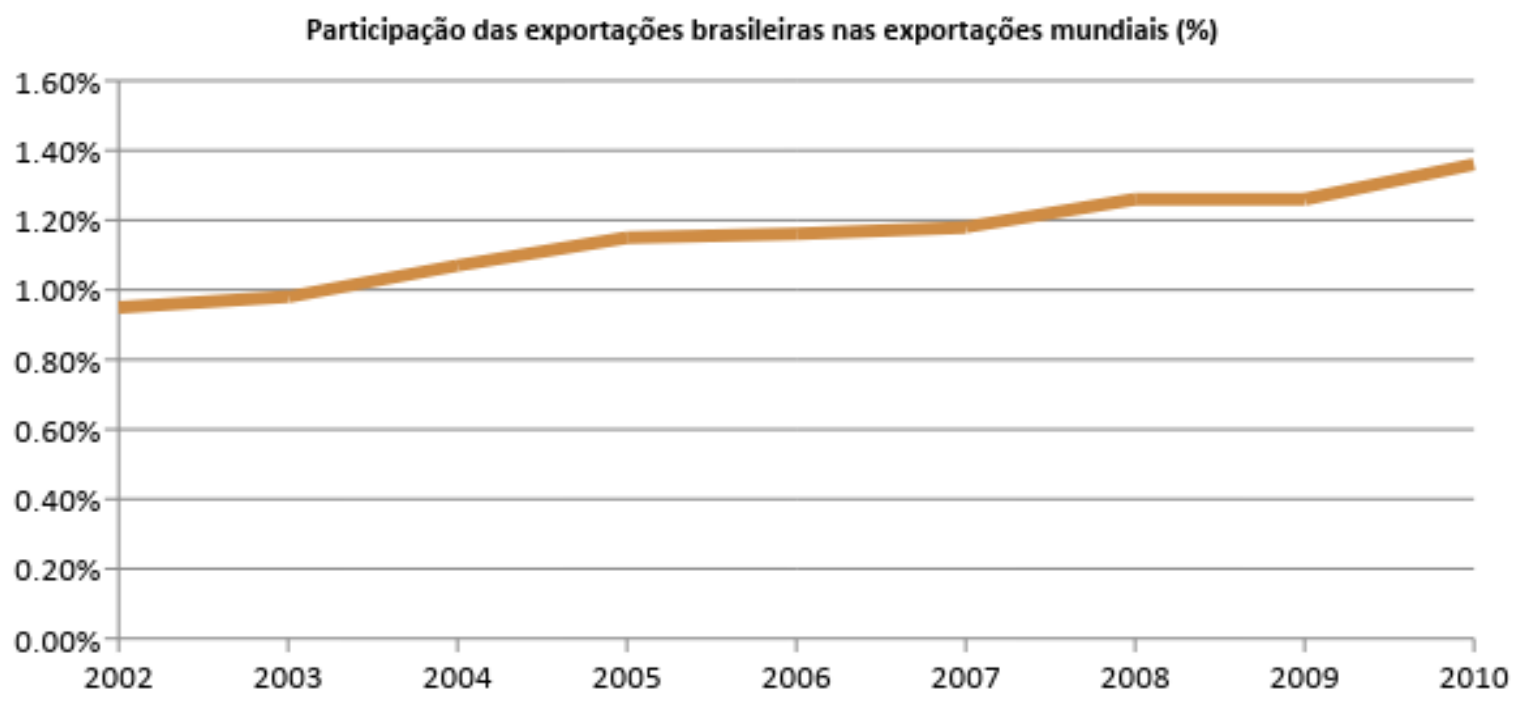

Gráfico 2 - Participação das exportações brasileiras nas exportações mundiais, 2002 - 2010 (\%) Fonte: Elaboração própria a partir de dados do Secex/MDIC.

Quando analisamos mais de perto a inserção externa brasileira percebemos, no intervalo de 2007-2010 uma queda de 25,5\% dos produtos manufaturados. Em contrapartida os produtos primários e semimanufaturados tiveram uma alta considerável de 56\% em 2007 para 67,2\% em 2010, favorecidos pela elevação mundial do preço das commodities.

O último tópico de resultados se relaciona com MPEs e sua inserção externa. A meta de aumento de 10\% não foi atingida devido ao cenário internacional de crise. Em 2008 e 2009 tivemos, respectivamente, uma redução de - 6,7\% e - 11,23\% no número das empresas participantes nas exportações. 


\section{Considerações finais}

Diante da revisão histórica, podemos perceber claramente a ruptura de ação do Estado brasileiro em relação aos rumos da economia: de um Estado industrializante, na última etapa do PSI no final da década de 1970, para um Estado estabilizador devido ao esgotamento de recursos e altas taxas inflacionárias - taxas essas que tirariam totalmente a credibilidade da(s) própria(s) moeda(s). A escolha por esse rumo teve um preço, com duas décadas de crescimento nacional medíocres.

Devemos, contudo, colocar a questão em perspectiva histórica. O Brasil, durante mais de 40 anos, foi um dos países que mais cresceu no mundo devido ao PSI, apesar de não ter realizado um dos fatores mais substantivos para o seu desenvolvimento econômico - a redistribuição de renda. As duas últimas décadas do século XX deixavam evidentes, ao menos, três fragilidades nacionais: a questão de financiamento e tamanho do estado na economia, o descompasso entre a ação dos agentes econômicos e a falta de eficácia de qualquer política monetária, dada a corrosão inflacionária. Entretanto, colocar a indústria brasileira totalmente de lado nas ações econômicas durante 20 anos proporcionou um atraso significativo no processo de produção, principalmente no contexto da revolução da microeletrônica, deixando o país cada vez mais atrasado em termos de produção, inovação e até mesmo arcabouço institucional.

A PITCE é um grande feito nos últimos tempos na indústria nacional. Primeiro, porque coloca em pauta, mais uma vez, os caminhos para o desenvolvimento e a função do estado nesse contexto; segundo, porque reconhece a importância da inovação para o processo industrial e que, para alcançar o nível produtivo mais alto, é preciso ter um objetivo claro e consciente de nação; e terceiro, mas não menos importante, é a reanimação e readequação regulatória e institucional para se propiciar mudanças significativas na estrutura nacional depois de anos sem uma orientação industrial clara.

Se a PITCE tem a virtude de utilizar políticas horizontais e verticais, mapeando setores estratégicos ainda não amadurecidos, e os já consolidados na estrutura nacional, para realizar uma evolução de longo prazo na indústria brasileira; o PDP, tem a qualidade de ser mais pragmático: metas claras e objetivas em 4 eixos macroeconômicos que deveriam ser 
Revista Catarinense de Economia -RCE

APEC - Associação dos Pesquisadores em Economia Catarinense

10 Semestre de 2018 - www.apec.pro.br/rce

consolidadas até 2010. Percebe-se pelas cifras destinadas para P\&D e pela inserção externa que o esforço, apesar de colocar na mesa uma agenda econômica necessária, é ainda insuficiente dada a defasagem produtiva brasileira. É preciso um esforço maior, apontado por diversos autores como Wilson Cano e Suzigan. A questão que não podemos perder der vista é: esforço em que dimensão e com qual custo?

Giambigi (2011) levantou a importância do tripé macroeconômico no final dos anos 1990 e início dos anos 2000, principalmente por evitar outros desdobramentos macroeconômicos em termos de crise. Do Plano Real ao tripé temos um intervalo de 5 anos de estabilização inflacionária. A continuidade desse tripé no Governo Lula colocou um descompasso nas medidas pretendidas e nos resultados verificados - sem contar a crise de 2008.

Em termos de desenvolvimento econômico, o governo Lula peca exatamente na execução - e talvez até na formulação - da política industrial. Temos um objetivo nacional claro (mesmo que a política macroeconômica seja contraditória) com uma participação ativa do Estado, mas de forma não tão eficiente quanto esperada. Temos um mapeamento de diversos setores considerados fundamentais ou essenciais para o desenvolvimento da indústria nacional, ao mesmo tempo que vultuosas quantias de crédito e subsídios - ausentando-se outros instrumentos para incentivo - são fornecidas, tanto para os setores e empresas considerados estratégicos como também para setores e empresas nacionais estabelecidas e competitivas, sobretudo para o setor alimentício e agropecuário. As políticas não preveem, ainda, nenhuma contrapartida para os agentes econômicos que não atingirem as metas estabelecidas, tornando o cenário inapropriadamente cômodo: acesso aos mais diversos recursos, sem uma ação efetiva do Estado em supervisionar os avanços setoriais.

No que se refere ao híbrido macroeconômico visto no Governo Lula entre estabilização e política industrial, não podemos (nem devemos, como mostra a história) negligenciar alguns fatores, como inflação e dívida pública. Esse trabalho reconhece e legitima - dentro do arcabouço teórico já mostrado - a ação do Estado para o amadurecimento industrial em busca de desenvolvimento em ações conscientes e planejadas, mas não a todo custo. Se, por um lado, o Tripé limitou as políticas industriais do Governo Lula com ações na dimensão macroeconômica que priorizavam a estabilidade (seja do câmbio, do superávit primário ou da própria inflação) ao invés do crescimento e aprimoramento industrial; por outro, concluiu o período de Governo com relativa estabilidade econômica e política - mesmo 
com a crise - e notáveis avanços sociais. Um dos caminhos, sem dúvidas, é a própria revisão do tripé sem largá-lo por inteiro: mudanças nos mecanismos de contenção inflacionária - e até mesmo nos prazos da meta estipulada - e, sobretudo, na taxa de juros nacional. O que não parece viável é um crescimento e uma marcha ao desenvolvimento, que ignore fatores problemáticos da história econômica recente.

\section{Referências}

ABDI. 2011 - Volume 1 - Balanço 2008-2010 - Macrometas PDP. Disponível em: <http://www.abdi.com.br/paginas/politica_industrial.aspx >. Acesso em: 02 set. 2017.

ABDI. Sumário Executivo PITCE. Setembro, 2007. Disponível em: <http://www.abdi.com.br/paginas/politica_industrial.aspx $>$. Acesso em: 12 set. 2017.

BANCO CENTRAL DO BRASIL. Indicadores econômicos consolidados. Disponível em: <http://www.bcb.gov.br/?INDECO > . Acesso em 6 de novembro de 2017.

CANO, W.; SILVA, A.L.G. Política industrial do governo Lula. IE/Unicamp, ${ }^{\circ}$ 181, Julho de 2010.

CAPES. Sistema de informações georreferenciadas. Disponível em: <https://geocapes.capes.gov.br/geocapes/>. Acesso em: 25 set. 2017.

CARNEIRO, R. Desenvolvimento em crise: a economia brasileira no último quarto de século São Paulo: Editora Unesp, 2002.

CASSIOLATO, J. E.; ERBER, F. S. Política industrial: teoria e prática no Brasil e na OCDE. Revista de Economia Política, v. 17, n. 2 (66), abr./jun. 1997.

CASTRO, A.B.; SOUZA, F.E.P. A Economia Brasileira em Marcha Forçada, Rio de Janeiro: Editora Paz e Terra, 1985.

COUTO, C.G.; ABRUCIO, F. O segundo governo FHC: coalizões, agendas e instituições. Tempo soc. vol.15 no.2 São Paulo Nov. 2003.

FERRAZ, J. C.; PAULA, G. M.; KUPFER, D. Política industrial. In: KUPFER, D.; HASENCLEVER, L. Economia industrial: fundamentos teóricos e práticas no Brasil. Rio de Janeiro: Campus, 2002. Cap. 23.

FERRAZ, M.B. Retomando o debate: A nova política industrial no Governo Lula. Planejamento e Políticas Públicas(ppp), n. 32, jan./jun. 2009.

FONSECA, P. C. D. Desenvolvimentismo: a construção do conceito. IN: DATHEIN, R. (Org.). Desenvolvimentismo: o conceito, as bases teóricas e as políticas. Porto Alegre: Editora da UFRGS, 2015.

GIAMBIAGI, F. Estabilização, Reformas e Desequilíbrios Macroeconômicos: Os Anos FHC (1995-2002). IN: GIAMIAGI, F.; CASTRO, L.B.; ERMANN, J. (org). Economia brasileira contemporânea (1945-2010), Elsevier, 2011. 
GUIMARÃES, E. A. A experiência recente da política industrial no Brasil: uma avaliação. Rio de Janeiro: Ipea, 1996 (Texto para Discussão n. 409).

IBGE. Contas Nacionais, 2003. Disponível em: $<$ https://ww2.ibge.gov.br/home/estatistica/pesquisas/pesquisa_resultados.php?id_pesquisa=48 $>$. Acesso em: 18 set. 2017.

KUPFER, D. Política industrial. Revista Econômica, Rio de Janeiro, v. 5, n. 2, p. 281-298, dez. 2003.

MATTOS, P.T.L. A formação do Estado regulador. Novos estudos, nº76, 2006.

MDIC. Estatísticas de comércio exterior. Disponível em: <http://www.mdic.gov.br/comercio-exterior/estatisticas-de-comercio-exterior>. Acesso em: 22 set. 2017.

NELSON, R., WINTER, S. An evolutionary theory of economic change, Belknap Press, Cambridge, 1982.

PLANALTO. LEI $N^{o}$ 11.105, DE $24 \quad D E$ MARÇO DE 2005. Disponível em: $<$ http://www.planalto.gov.br/ccivil_03/_ato2004-2006/2005/lei/111105.htm>. Acesso em 8 de novembro de 2017.

PINTEC. Publicação Pintec 2008. Disponível em: $<$ http://www.pintec.ibge.gov.br/index.phpoption=com_content\&view=article\&id=45\&Itemid $=12$ > . Acesso em: 20 set. 2017.

SALERNO, M.S.; DAHER, T. (2006). Política Industrial, Tecnológica e de Comércio Exterior do Governo Federal (PITCE): Balanço e Perspectivas. Brasília, 23-set.

SARTI, F.; LAPLANE, M. Política de desenvolvimento produtivo, grau de investimento e fundo soberano: elementos para uma estratégia de investimento e desenvolvimento. Boletim NEIT (Núcleo de Economia Industrial e da Tecnologia), n. 11, mai.jun. 2008.

SUZIGAN, W. Industrialização a visão de Celso Furtado. Instituto de Economia/UNICAMP, 2001.

SUZIGAN, W.; FURTADO, J. Política industrial e desenvolvimento. Revista de Economia Política, v. 26, n. 2 (102), p. 163-185, abr./jun. 2006.

SUZIGAN, W. Estado e industrialização no Brasil. Revista de Economia Política, v. 8, n. 4, p. 5-16, out./dez. 1988. 